184 Bericht: Allgemeine analytische Methoden, analyt. Operationen etc.

\title{
Einen Schwefelwasserstoffapparat zur Entwicklung grösserer
} Gasmengen beschreibt G. A. Goyder ${ }^{1}$ ). Der Apparat, welcher bei grosser Sparsamkeit gut und sicher functioniren soll, besteht aus einem hoch stehenden Säurereservoir, dessen unterer Tubulus durch ein dünnes Rohr und einen kräftigen Schlauch mit einem Quecksilberventil verbunden ist. Das letztere ist direct an der Entwicklungsflasche angeschlossen. Das Quecksilber lässt Säure in das Entwicklungsgefäss eintreten, sperrt aber den weiteren Zufluss ab, sobald sich in dem Gefäss ein genügender Ueberdruck bemerkbar macht. Die verbrauchte Säure kann immer abgelassen werden. Die Entwicklungsflasche steht ferner durch einen anderen Tubulus mit einer zweiten Quecksilbersperrung in Verbindung, durch die nur dann Gas entweicht, wenn der Apparat nach dem Gebrauch geschlossen wird; ferner ist sie verbunden mit einer Watte enthaltenden Woulf'schen Flasche und diese mit einer zweiten mit Wasser gefüllten, an welcher man durch Oeffnen eines Hahnes mit Schwefelwasserstoff gesättigtes Wasser entnehmen kann. Dieser Flasche folgt dann eine längere Röhre mit verschiedenen Ansätzen, die zur Verbindung mit denjenigen Gefässen dienen, in welchen man Fällungen vorzunehmen beabsichtigt. Der Apparat kann natürlich auch zur Entwicklung anderer Gase dienen; das zwischen Säurereservoir und Entwicklungsgefäss befindliche Quecksilberventil kann verschiedene Form haben.

Ueber die Verwendung von Phenolphtaleïn und Methylorange bei Titrationen hat M. Bidwell Breed ${ }^{2}$ ) Versuche angestellt, bei denen er ähnliche Beobachtungen bezüglich des Phenolphtaleïns machte wie Scheiding ${ }^{3}$ ). Dem Methylorange gibt der Verfasser den Vorzug, weil dieses nach seiner Ansicht eben so empfindlich wie Phenolphtaleïn ist und sich ausserdem, ohne durch die Gegenwart von Kohlensäure beeinflusst zu werden, anwenden lässt. Mit Phenolphtaleïn kann man nur dann richtige Resultate erhalten, wenn man nach erfolgter Neutralisation kocht und die dabei wieder auftretende Rothfärbung durch erneuten Säurezusatz zum Verschwinden bringt. Bezüglich dieses Punktes verweise ich auf die von Dobriner ${ }^{3}$ ) vor einiger Zeit veröffentlichte Arbeit, die einen weit kürzeren Weg enthält, um mit Phenolphtaleïn richtige Werthe zu erhalten. Im übrigen sei z. B. an die Arbeiten von

1) The Journ. of analyt. and applied chemistry 7, 194.

2) The Journ. of analyt. and applied chemistry 7, 204.

3) Diese Zeitschrift 35, 336. 
R. Thomson ${ }^{1}$ ) erinnert, in denen die principiell verschiedenartige Anwendbarkeit und Eigenthümlichkeit beider Indicatoren dargelegt ist.

Zur Herstellung einer haltbaren Lösung von citronensaurem Ammon empfiehlt R. de Roode ${ }^{2}$ ) den Zusatz einer kleinen Menge Salicylsäure, etwa $1 g$ für $5 l$ der Lösung. Zweckmässig neutralisirt man die Salicylsäure mit dem zu verwendenden Ammoniak. Die fertige Lösung hält sich unbegrenzt lange und die sonst auftretende Pilzbildung wird ganz und gar vermieden.

Der Verfasser findet es angenehm, eine genau neutrale Lösung anzuwenden und erhält eine solche, wenn er die Citronensäure in 10 procentigem Ammoniak löst und die heisse Lösung mit Ammoniak ubersättigt. Bleibt dieselbe über Nacht offen stehen, so erweist sie sich nachher genau neutral, da der Ueberschuss des Ammoniaks aus der heissen Lösung entweicht.

\section{Chemische Analyse anorganischer Körper.}

\section{Von \\ H. Weber}

Ueber das Argon. Lord Rayleigh ${ }^{3}$ ) hatte bei Untersuchungen über die Dichte der wichtigsten Gase gefunden, dass das specifische Gewicht des atmosphärischen Stickstoffs wesentlich höher ist als dasjenige des Stickstoffs, welcher aus chemischen Verbindungen dargestellt ist.

Im Verlaufe seiner nun in Gemeinschaft mit Ramsay unternommenen Versuche entdeckte dann Rayleigh, dass in der That in der Luft neben dem Stickstoff noch ein anderer Bestandtheil enthalten ist, der sich sowohl chemisch, wie physikalisch (Spectrum) wesentlich vom Stickstoff unterscheidet und sich in Folge seiner chemischen Trägheit von diesem trennen lässt. $\mathbf{R}$ ayleigh und $\mathbf{R}$ amsay nannten diesen Restbestandtbeil »Argon « und fanden, dass dessen Menge in der Luft etwa ein Procent des vorhandenen Stickstoffs beträgt.

1) Vergl. diese Zeitschrift 24, 222 und 27, 47.

2) The Journ. of the Americ. chem. Soc. 17, 47.

3) Chem. News 69, 281. 